Check for updates

Cite this: Nanoscale Adv., 2019, 1, 4268

Received 13th June 2019

Accepted 16th September 2019

DOI: 10.1039/c9na00371a

rsc.li/nanoscale-advances

\section{Dynamic surface properties of PEG-coated CuS nanoparticles alter their interaction with cells as revealed by surface-enhanced infrared spectroscopy $\dagger$}

\author{
Fengjuan Cao, (D) ab Lie Wu, (D) a Xiaofei Zhang, ${ }^{\text {ac }}$ Shanshan Li, ${ }^{\text {ac }}$ Chao Wang, ${ }^{\text {ac }}$ \\ Wenyao Zhen (iD ${ }^{\text {ac }}$ and Xiue Jiang (iD *abc
}

\begin{abstract}
Characterization of the dynamic changes of the basic surface properties of nanoparticles is of great significance to reveal the interaction mechanism between nanoparticles and cells; however, it is often neglected due to the limitations of existing analytical methods. This knowledge has been renewed by using surface enhanced infrared absorption spectroscopy (SEIRAS) to study the interaction between PEG-CuS nanoparticles and living cells attached to rGO-Au modified Au films. Based on the difference spectra of cell membranes and the associated water, we clearly revealed that $\mathrm{Cu}^{2+}$ ions produced by the degradation of PEG-CUS can coordinate with PEG, thus changing the interaction between nanoparticles and cells including how and how many nanoparticles enter the cells and the sequential photothermal effect, which breaks through the limitations of the present analytical methods.
\end{abstract}

\section{Introduction}

The rapid development of nanotechnology has greatly promoted the application of nanomaterials in the field of biomedicine, ${ }^{1,2}$ which stimulates the study of interactions between cells and nanomaterials with different sizes, shapes, surface charges and hydrophobic properties. ${ }^{3,4}$ However, most studies are based on the assumption that the surface properties of nanoparticles are relatively stable over a period of time. Unfortunately, the cell interface could be continuously changed due to housekeeping of cells, ${ }^{5}$ thus changing the interactions at the nano-cell interface, ${ }^{6}$ which has suggested the importance of characterizing dynamic changes in basic surface properties that

${ }^{a}$ State Key Laboratory of Electroanalytical Chemistry, Changchun Institute of Applied Chemistry, Chinese Academy of Science, Changchun 130022, Jilin, China. E-mail: jiangxiue@ciac.ac.cn

${ }^{b}$ University of Chinese Academy of Sciences, Beijing 100049, China

'Department of Chemistry, University of Science and Technology of China, Anhui 230026, China

$\dagger$ Electronic supplementary information (ESI) available. See DOI: 10.1039/c9na00371a are often overlooked. For instance, polyethylene glycol (PEG) has been extensively used to modify nanomaterials to improve the blood circulation time of nanomaterials due to good resistance to protein adsorption and avoidance of macrophage uptake, ${ }^{7}$ while less is known about the dynamic surface properties when PEG was used to modify degradable nanomaterials and even less about the subsequent effect on the nano-cell interactions. ${ }^{8}$ One of the obstacles may be that the current research on the interaction of nano-cells mostly relies on microscopy analysis including fluorescence confocal microscopy, atomic force microscopy, dark field microscopy etc., ${ }^{3,9,10}$ These techniques can provide visual information for the studied interactions, but they cannot illustrate the chemical information of the subtle changes in the surface properties of nanomaterials at the molecular level, making it difficult to give noticeable differential signals that could attract dramatic attention. Therefore, the nano-cell interactions should be viewed in a broader context than simple vesicular trafficking and considered more carefully by combination of multiple analytical techniques.

Fourier transform infrared (FTIR) spectroscopy, ${ }^{11}$ as a powerful nondestructive label-free fingerprinting tool measuring infrared light absorbed by molecules through the transient dipole moment change, has successfully attracted a lot of attention in analysis of biochemical materials, ${ }^{12-14}$ including conformational changes of proteins, ${ }^{15,16}$ tissue classification ${ }^{17,18}$ and cancer identification, ${ }^{19,20}$ among many others. The SEIRAS technique in when used with a plasmonic nanostructure greatly enhances the sensitivity of the conventional FTIR spectroscopic technique toward molecules adsorbed on a nanostructure by virtue of the electromagnetic-field enhancement effect, thus enabling measurements of minute spectral changes in live biological samples and monitoring of dynamic behaviors in real time without the requirement of additional reporter groups. ${ }^{18,21}$ Besides, by combining the advantage of the tremendous IR extinction coefficient of water molecules, we could further investigate the minute absorption change of interfacial water bound to membranes based on the 
optical near-field effect of SEIRAS. ${ }^{22,23}$ Various types of noble metal nanomaterials and graphene-based plasmonic substrates have been developed to further improve the analytical sensitivity of SEIRAS for sulfhydryl-containing molecules and aromatic molecules. ${ }^{\mathbf{2 4 , 2 5}}$ Thus, the hybrid plasmonic substrates of metal and graphene-based nanomaterials will greatly expand the types of detected molecules, and the introduction of rGO will be beneficial to capture cells ${ }^{26}$ for the analysis by SEIRAS on the biointerface due to its roughness and low stiffness nature.

Herein, we prepared a hetero Au-rGO-decorated Au film on a silicon substrate via simultaneous chemical reduction of $\mathrm{Au}$ and GO as an attractive plasmonic nanostructure for attachment of living cells, which shows good biocompatibility toward cultured living cells after being pretreated with poly-L-lysine (PLL). Based on this model, we systematically studied the interaction of cells with PEG-coated CuS nanoparticles (PEGCuS NPs) that have been extensively applied in cancer photothermal therapy due to their high photothermal stability. Surprisingly, we found that for newly prepared CuS NPs (CuSnew) and nanomaterials kept for more than 7 days (CuS-old), their interactions with cells induce a significant difference in SEIRA spectra. It mainly resulted from the change of the surface properties of nanomaterials caused by the coordination of copper ions produced during the degradation of CuS NPs. This difference in surface properties significantly alters the interaction between nanomaterials and cell membranes, the pathway and the number of nanoparticles entering the cells, and the photothermal effect on cancer cells. Our results have led us to rethink the biological effects of nanoparticles. Some reports suggest that the Fenton effect or enzymatic effect of nanomaterials may be due to the coordination of metal ions in biological fluid with surface modification molecules of nanomaterials, rather than the nanomaterials themselves.

\section{Results and discussion}

\section{Synthesis and characterization of a rGO-Au/Au plasmonic substrate}

The Au film decorated with rGO-Au (rGO-Au/Au) was in situ deposited onto a freshly prepared hydrophobic Si substrate (Fig. 1A, stage I) by reducing the mixture of well-characterized GO (Fig. S1†) and $\mathrm{NaAuCl}_{4}$ solution at $55{ }^{\circ} \mathrm{C}$ for $4 \mathrm{~min}$ using a reductant consisting of $0.3 \mathrm{M} \mathrm{Na}_{2} \mathrm{SO}_{3}, 0.1 \mathrm{M} \mathrm{Na}_{2} \mathrm{~S}_{2} \mathrm{O}_{3}, 0.1 \mathrm{M}$ $\mathrm{NH}_{4} \mathrm{Cl}$ and $3 \% \mathrm{HF}$ aqueous solution (Fig. 1A, stage II). The reduction of GO was characterized by $\mathrm{X}$-ray photoelectron spectroscopy (XPS). As shown in Fig. 1A, the high-resolution C 1s spectra of $\mathrm{GO}$ and $\mathrm{rGO}-\mathrm{Au} / \mathrm{Au}$ can be fitted with five components including $\mathrm{C}-\mathrm{C} / \mathrm{C}=\mathrm{C}(284.5 \mathrm{eV}), \mathrm{C}-\mathrm{OH}(285.5 \mathrm{eV})$, $\mathrm{C}-\mathrm{O}(286.6 \mathrm{eV}), \mathrm{C}=\mathrm{O}(287.8 \mathrm{eV})$, and $\mathrm{O}-\mathrm{C}=\mathrm{O}(289 \mathrm{eV}),{ }^{27-29}$ which shows a clear decrease for the peak intensities of oxygenated carbon of $\mathrm{GO}$ in $\mathrm{Au}$, suggesting that GO was simultaneously reduced via the chemical deposition process upon the formation of the plasmonic substrate. The scanning electron microscopy (SEM) image, X-ray energy dispersive spectroscopy (EDS) spectrum and elemental mapping image of $\mathrm{Au}$ and $\mathrm{C}$ clearly reveal the non-uniform distribution of rGO (C element) on the substrate of $\mathrm{Au}$ (Fig. 1B). Many $\mathrm{Au}$

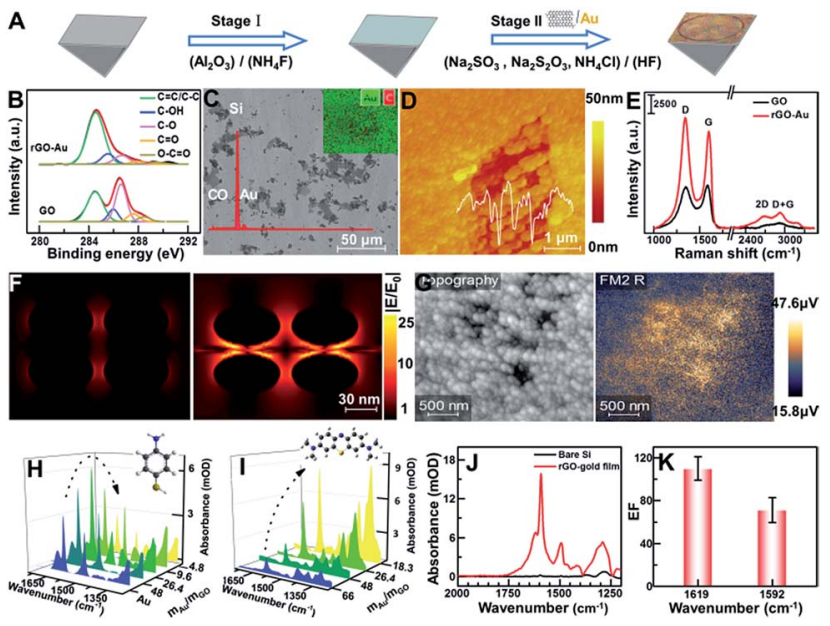

Fig. 1 (A) Schematic of fabrication of the $\mathrm{rGO}-\mathrm{Au} / \mathrm{Au}$ plasmonic substrate on the Si prism. (B) The C1s XPS spectrum of rGO-Au/Au and GO with experimental (black line) and fitted curves (red line) including deconvoluted components. (C) SEM image, EDS spectrum and elemental mapping image of the $\mathrm{rGO}-\mathrm{Au} / \mathrm{Au}$ substrate (Au: green; $\mathrm{C}$ : red). (D) The typical AFM image of the $\mathrm{rGO}-\mathrm{Au} / \mathrm{Au}$ substrate and corresponding height profile. (E) Raman spectra of GO and $\mathrm{rGO}-\mathrm{Au} / \mathrm{Au}$ under $532 \mathrm{~nm}$ laser irradiation. (F) FDTD simulations of the electric field amplitude distribution $\left|E / E_{0}\right|$ of AuNPs/AuNPs and AuNPs/rGO/AuNPs at $\lambda=5.7 \mu \mathrm{m}$. (G) Mid-infrared near-field amplitude image of the asprepared $\mathrm{rGO}-\mathrm{Au} / \mathrm{Au}$ substrate measured with $\mathrm{s}-\mathrm{SNOM}$ at $\lambda=5.7 \mu \mathrm{m}$. $\left(\mathrm{H}\right.$ and I) SEIRA spectra of $p$-ATP $\left(10^{-3} \mathrm{M}\right)$ and MB $\left(10^{-5} \mathrm{M}\right)$ molecules adsorbed on the $\mathrm{rGO}-\mathrm{Au} / \mathrm{Au}$ substrate prepared with different mass ratios of $\mathrm{Au}$ and $\mathrm{GO}$. ( $\mathrm{J}$ and $\mathrm{K}$ ) A comparison of the enhanced spectra for $0.32 \mu \mathrm{g} p$-ATP with and without the $\mathrm{rGO}$-Au/Au film on the Si prism (J) and the corresponding average enhancement factor (EF) at 1619 and $1592 \mathrm{~cm}^{-1}(\mathrm{~K})$.

nanoparticles were adsorbed on the decorated rGO and further formed some irregular nanoscale pores as shown in the atomic force microscopy (AFM) image (Fig. 1C). The Raman spectra show that the relative intensity $I_{\mathrm{D}} / I_{\mathrm{G}}$ between the $\mathrm{D}$ band at $\sim 1599 \mathrm{~cm}^{-1}$ and the $\mathrm{G}$ band at $\sim 1344 \mathrm{~cm}^{-1}$ increased from 0.95 to 1.14 in the reduction process of GO, suggesting that numerous graphitic domains with a smaller size are newly formed by the reduction of oxygenated carbon, which are anchored by $\mathrm{Au}$ nanoparticles, thus greatly enhancing the $\mathrm{D}$ band and resulting in the irregular adsorption of $\mathrm{Au}$ nanoparticles. ${ }^{29-31}$ According to the peak position of the second-order Raman D-peak, $f(2 \mathrm{D}) \sim 2676 \mathrm{~cm}^{-1}$, the thickness of rGO in the $\mathrm{rGO}-\mathrm{Au} / \mathrm{Au}$ structure could be deduced to be 3-5 layers (Fig. 1D). ${ }^{32}$

To fully verify the role of graphene-enhanced plasmons in a local electromagnetic field, a simplified model of ellipsoid gold nanoparticles $\left(R_{1}=30 \mathrm{~nm} ; R_{2}=10 \mathrm{~nm}\right)$ obtained from the AFM image and a rGO layer of $4 \mathrm{~nm}$ thickness inferred from Raman data were built, and the corresponding local field distribution $\left|E / E_{0}\right|$ was simulated by the finite-difference timedomain (FDTD) method, as shown in Fig. 1E. Comparison of the $X-Z$ views of the electric field amplitude distribution in both AuNPs/AuNPs and AuNPs/rGO/AuNPs shows that a stronger local field enhancement clearly appears between AuNP and rGO and at both sides of the AuNPs, indicating that the addition of 
rGO greatly enhances the local field intensity in the plasmonic hybrid structure. ${ }^{33,34}$ To further understand this phenomenon, scattering-type scanning near-field optical microscopy (sSNOM) was used to simultaneously map the topography and the nearfield scattered intensity of the as-prepared $\mathrm{rGO}-\mathrm{Au} / \mathrm{Au}$ substrate at $\lambda=5.7 \mu \mathrm{m}$ (Fig. 1F). In the infrared near-field image, the scattering amplitude of rGO-AuNP/Au located in the nanoscale pores shown in the topography image is much higher than that of the surrounding $\mathrm{Au}$, possibly due to the rGO-mediated enhancement of the local electronic field and their coupling. The mass ratios of Au and GO could be tailored according to detection needs to obtain an optimal enhancement. For sulfhydryl-containing molecules such as $p$-aminothiophenol ( $p$ ATP), ${ }^{35}$ which can form self-assembled monolayers on a gold surface by a favorable interaction between $\mathrm{Au}$ and sulfur groups, the maximum absorption of $p$-ATP can be obtained on the rGO$\mathrm{Au} / \mathrm{Au}$ substrates prepared by using gold and $\mathrm{GO}$ at a mass ratio of 26.4 (Fig. 1G). Meanwhile, for the detection of aromatic molecules like methylene blue (MB) ${ }^{36}$ which can be adsorbed on rGO via $\pi-\pi$ stacking, the absorption was increased with the increase of the rGO content in the plasmonic substrate (Fig. 1H). Considering comprehensively, the mass ratio of $\left(m_{\mathrm{Au}} /\right.$ $\left.m_{\mathrm{GO}}=26.4\right)$ was chosen for preparing the plasmonic substrate for further application. The enhancement effect was evaluated by comparing the characteristics of the deposited $p$-ATP $(\sim 0.32$ $\mu \mathrm{g}$ ) onto the bare $\mathrm{Si}$ prism and $\mathrm{rGO}-\mathrm{Au} / \mathrm{Au}$ coated Si prism, respectively, at about monolayer thickness (Fig. 1I) ${ }^{25}$ which shows the enhancement factor of $\sim 110$ and 72 times by comparing the peak intensity at 1619 and $1592 \mathrm{~cm}^{-1}$ (Fig. 1J).

\section{Cell immobilization on the rGO-Au/Au substrate}

To enhance the attachment of cells on the rGO-Au/Au substrate, we further modified the substrate with a biocompatible extracellular matrix PLL (Fig. 2A), because its flexible molecular backbone with plentiful active amino groups can bind tightly to negatively charged cell membranes. ${ }^{37}$

The PLL thin layer was well deposited on the substrate as proved by the in situ SEIRAS measurements. The SEIRA spectra show a gradual increase of the significant absorption feature of $\nu(\mathrm{C}=\mathrm{O})$ at $1660 \mathrm{~cm}^{-1}$ and the combination of $\mathrm{N}-\mathrm{H}$ in-plane bending and the $\mathrm{C}-\mathrm{N}$ stretching vibration at $1545 \mathrm{~cm}^{-1}$ at the beginning of $30 \mathrm{~min}$ and then a slower growth mode until reaching equilibrium (Fig. 2B). ${ }^{38,39}$ When washed with ultrapure water six times after $6 \mathrm{~h}$, the absorption intensity of PLL was almost unchanged, indicating that the PLL thin layer was formed and was stable (Fig. 2B, inset). This observation was in agreement with the AFM results showing that the root mean square roughness $\left(R_{\mathrm{a}}\right)$ decreases from $4.86 \mathrm{~nm}$ for the rGO-Au/ $\mathrm{Au}$ film to $3.17 \mathrm{~nm}$ for the PLL monolayer (Fig. 2C). After introducing HeLa cells into the ATR chamber, cell attachment, growth, and proliferation occurred on the $\mathrm{rGO}-\mathrm{Au} / \mathrm{Au}$ surface coated with the PLL layer. An $\sim 100 \%$ confluent cell monolayer with a circular smooth and bright edge was observed in the AFM optical image (Fig. 2E), suggesting a good biocompatibility as confirmed using the trypan blue exclusion test (Fig. 2F), which showed about $99 \%$ viable cells.

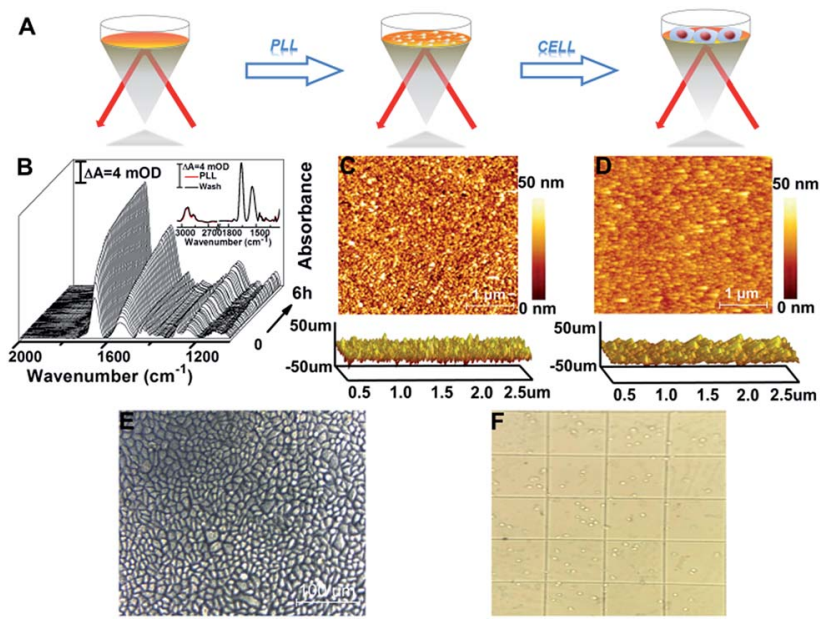

Fig. 2 (A) Schematic of PLL coating and of HeLa cell assembly on the substrate. (B) Time-dependent SEIRA spectra of PLL were obtained by taking the $\mathrm{rGO}-\mathrm{Au} / \mathrm{Au}$ substrate immersed in $\mathrm{H}_{2} \mathrm{O}$ as a reference spectrum. Inset: comparison of spectra before and after washing with water. (C and D) The typical 2D and 3D AFM images of the microscopic features on the surface of the $\mathrm{rGO}-\mathrm{Au} / \mathrm{Au}$ film (C) and PLL coated $\mathrm{rGO}-\mathrm{Au} / \mathrm{Au}$ film (D). (E) An optical microscopy image showing a $100 \%$ confluent HeLa cell monolayer successfully immobilized on the rGO-Au/Au substrate. (F) The image of trypan blue exclusion test cells which were trypsinized from the rGO-Au/Au substrate.

\section{The interaction of cells and PEG-coated CuS NPs monitored by SEIRAS}

After this, the spectrum of cells immersed in $1 \mathrm{~mL}$ phosphatebuffered saline (PBS, $\mathrm{pH}=7.4$ ) was taken as the reference, and then sample spectra were measured as soon as the cells were exposed to $100 \mu \mathrm{g} \mathrm{mL}{ }^{-1}$ PEG-CuS NPs. ${ }^{40}$ For comparison, the sample spectra following the addition of NPs with the spectrum of PLL coating as the reference were also recorded in PBS (Fig. 3A(a)). As can be seen, the SEIRA spectra induced by the addition of PEG-CuS NPs are significantly different in the presence and absence of cells, indicating that the spectra shown in Fig. $3 \mathrm{~A}(\mathrm{~b}$ and $\mathrm{c})$ were indeed caused by the interaction between HeLa cells and NPs, particularly at IR bands associated with proteins and phospholipids, which are not disturbed by structure peaks of PLL and adsorbed PEG-CuS NPs. After treating with CuS NPs for $2 \mathrm{~h}$, cells still maintain good activity validated by cell viability experiments of MTT and the trypan blue exclusion test (Fig. S3†). Because the evanescent wave decays exponentially with the distance from the surface of the $\mathrm{Si}$ prism where single total infrared reflection occurs, IR light could penetrate into cell volume only at a very shallow depth, such that the observed SEIRA spectra should mostly come from the rearrangements of the cell membrane, such as membrane proteins, lipids $e t c .{ }^{41,42}$ It is worthy to note that addition of newly prepared CuS NPs (CuS-new) will induce some characteristic peaks in the fingerprint region (Fig. $3 \mathrm{~A}(\mathrm{~b})$ ) including the peaks at 1663 and $1542 \mathrm{~cm}^{-1}$ assigned to amide I and amide II band vibrations and the peaks at $1446-1358 \mathrm{~cm}^{-1}$ assigned to conformational changes of the lipid bilayer (Table S1 $\dagger$ ). However, addition of nanomaterials that have been preserved 

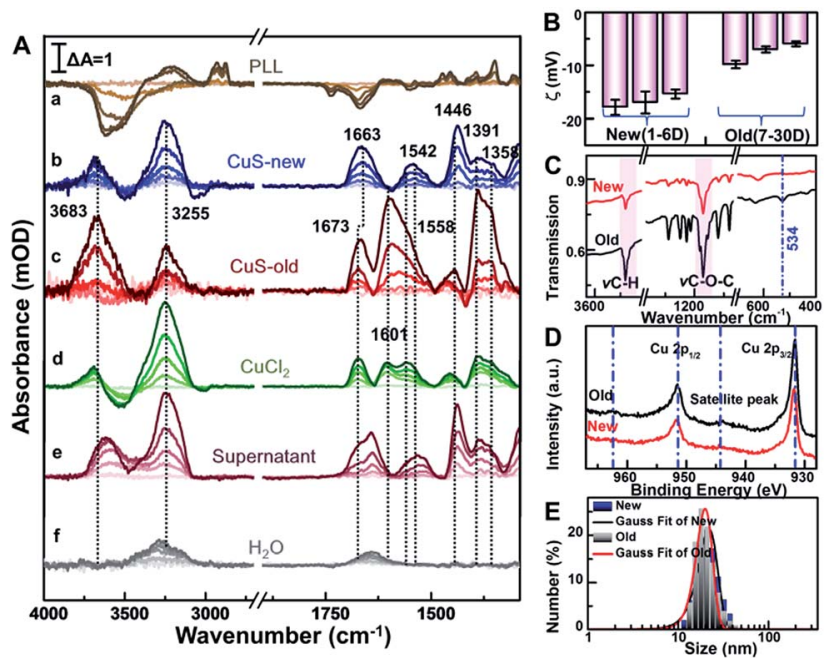

Fig. 3 (A) The SEIRA difference spectra of (a) CuS NP induced PLL by taking the PLL layer modified substrate as a reference, and the difference spectra of HeLa cells induced by addition of (b) CuS-new NPs, (c) CuS-old NPs, (d) $\mathrm{CuCl}_{2}$, (e) the supernatant of CuS-old NPs and (f) only water as a control by taking the cell incubated substrate as a reference for $2 \mathrm{~h}$, respectively. (B) The zeta potentials of PEG-CuS NPs at different times. (C) FTIR transmission spectra of the CuS-new NPs and CuS-old NPs. (D) Cu 2p XPS spectra of the CuS-new NPs and CuS-old NPs. (E) The hydrodynamic diameter distributions of CuSnew NPs and CuS-old NPs using the dynamic light scattering technique.

for more than 7 days (CuS-old) could induce a dramatic difference in the spectrum (Fig. 3A(c)). Two peaks appeared at 1500$1700 \mathrm{~cm}^{-1}$ with maxima at $1673 \mathrm{~cm}^{-1}$ and $1601 \mathrm{~cm}^{-1}$, respectively. The difference of amide I will be discussed vide infra. Surprisingly, the CuS-old-induced characteristic peaks in the fingerprint region $(\sim 1673,1601,1558,1446,1391$, and 1358 $\mathrm{cm}^{-1}$ ) are nearly consistent with those induced by addition of $\mathrm{CuCl}_{2}$ solution (Fig. 3A(d)), especially when the broad peak at $1601 \mathrm{~cm}^{-1}$ was analyzed by Gaussian curve fitting (Fig. S5†) suggesting that a similar interaction mode with copper ions happened. As we know, $\mathrm{Cu}$ is an indispensable trace element that drives various kinds of life activities. ${ }^{43}$ When cells uptake $\mathrm{Cu}$, reduction of $\mathrm{Cu}$ occurs prior to its transport through the plasma membrane. First, $\mathrm{Cu}$ ions probably interacted with cell surface metalloreductases Fre1p/2p (heme-containing proteins, four histidine residues, etc.), ${ }^{\mathbf{4 4 , 4 5}}$ which reduce $\mathrm{Cu}^{2+}$ (oxidized) to $\mathrm{Cu}^{+}$(reduced) via the coordination of $\mathrm{Cu}^{2+}$ ions and nitrogen or oxygen donors. ${ }^{43}$ Subsequently, transmembrane copper transport protein 1 (Ctr1) coordinates $\mathrm{Cu}^{+}$ions through the sulfur donor ligand ${ }^{\mathbf{4 3 , 4 6}}$ in the high affinity methionine-rich domains " ${ }^{40}$ MMMMPM ${ }^{45 "}$ and "150 MLIFM ${ }^{154 " . ~ A c c o r d i n g ~ t o ~ t h e ~ m e c h a-~}$ nism discussed above, the absorption peak at $1601 \mathrm{~cm}^{-1}$ was very likely from the coordination of $\mathrm{Cu}^{2+}$ ions with nitrogen or oxygen donors such as from histidine moieties ${ }^{\mathbf{4 3 , 4 7}}$ and/or from other components in the membrane. Indeed, the coordination of $\mathrm{Cu}^{2+}$ with nitrogen or oxygen donors could result in the absorption at about 1610-1580 $\mathrm{cm}^{-1} \cdot{ }^{16,48,49}$ Therefore, the appearance of the $1601 \mathrm{~cm}^{-1}$ peak could be closely related to coordination of copper ions and the cell membrane, which also resulted in a similar conformational change of protein as reflected by an identical peak at $1673 \mathrm{~cm}^{-1}$.

Meanwhile, to identify if it comes from the free copper ions in the CuS-old solution, we further centrifuged the solution of CuS-old and recorded the spectrum induced by the interaction between the supernatant and cells (Fig. 2A(e)). However, we did not find characteristic peaks similar to those induced by copper ions. In contrast, the changes of characteristic peaks in the fingerprint region were similar to those induced by cell interaction with CuS-new nanoparticles. All of this suggests that the different peaks that have been induced by CuS-new and CuS-old nanoparticles originated from the difference in their surface properties, and have a relationship with copper ions.

To gain a more detailed understanding, we thoroughly characterized the PEG-CuS NPs. We found that zeta potential of newly prepared nanoparticles (Fig. 3B) remained nearly unchanged for 6 days (new), while it became more positive after 7 days and then became constant within 30 days (old), which is due to the dissociation of $\mathrm{Cu}$ ions from $\mathrm{CuS}$ and then coordination with PEG of CuS NPs because a clear $\nu(\mathrm{Cu}-\mathrm{O})$ absorption peak at $534 \mathrm{~cm}^{-1}$ was observed in the FTIR spectrum of CuS-old NPs which was not observed for CuS-new NPs (Fig. 3C). In order to verify this, we further use the XPS technique, a useful analysis tool for characterizing surface element states, to detect different periods of CuS NPs. As we can see, in the XPS survey spectra (Fig. 3D), the more prominent satellite peaks for CuS-old NPs at around $944.2 \mathrm{eV}$ and $962.6 \mathrm{eV}$ demonstrate the existence of $\mathrm{Cu}(\mathrm{II})$ in the paramagnetic chemical state on the surface of $\mathrm{CuS}$ $\mathrm{NPs},{ }^{50}$ further indicating that more $\mathrm{Cu}^{2+}$ species existed on the surface of PEG-CuS NPs. Nevertheless, such changes in the surface properties only slightly changed the diameter of the PEG-CuS NPs $(\sim 2 \mathrm{~nm})$ as judged from dynamic light scattering (Fig. 3E). And a more detailed characterization of CuS-new NPs and CuS-old NPs is shown in Fig. S3† (including TEM, HRTEM, EDS, UV-Vis, etc.). We also noted that interaction of $\mathrm{Cu}$ ions (d) and CuS-new (b) with cells induced a strong peak at $3255 \mathrm{~cm}^{-1}$ and a weak peak at $3683 \mathrm{~cm}^{-1}$, which are assigned to vibrations of water molecules in an effective and disturbed hydrogen-bond network, respectively (Table $\mathrm{S} 1 \dagger$ ), ${ }^{\mathbf{5 1 , 5 2}}$ and the absorption peak at $3250 \mathrm{~cm}^{-1}$ may also be attributed to the amide A band of the protein (Fig. S4 $\dagger$ ). ${ }^{53}$ The water peaks at $3255 \mathrm{~cm}^{-1}$ were also observed in the control group with only addition of $25 \mu \mathrm{L} \mathrm{H}_{2} \mathrm{O}$ (Fig. 3A(f)) possibly due to the influence of the plasma membrane surface potential $(\psi)$ on the alignment of the interfacial water. ${ }^{5,55}$ Therefore, its strength is naturally affected by the different changes of local potential caused by the interaction of different substances with cell membranes. The appearance of the peak at $3683 \mathrm{~cm}^{-1}$ could be attributed to the penetration of water molecules into the hydrophobic region of the disordered lipid due to the interaction of the $\mathrm{Cu}$ ions and CuS-new NPs. ${ }^{56}$ It is worthy to note that the intensity of the peak was greatly enhanced after the cells interacted with CuS-old NPs.

To further reveal the origin of the difference, the intensities of peaks at 3255 and $3683 \mathrm{~cm}^{-1}$ versus incubated time were dynamically tracked after addition of CuS-new and CuS-old NPs, respectively (Fig. 4A-D). For addition of CuS-new NPs, both peak 
A
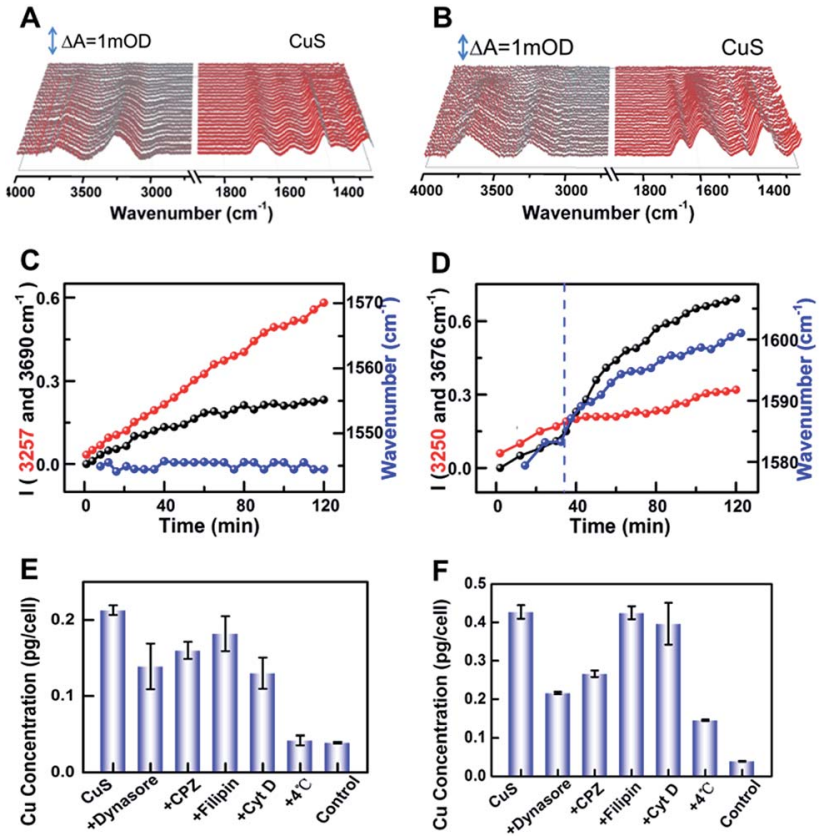

Fig. 4 (A and B) The CuS-new NP (A) and CuS-old NP (B) induced SEIRA difference spectra by taking HeLa cells on the $\mathrm{rGO}-\mathrm{Au} / \mathrm{Au}$ substrate immersed in PBS as a reference. ( $C$ and $D)$ IR peak intensity of interfacial water and the shifts of the maximum peak position at $\sim 1542$ $\mathrm{cm}^{-1}$ were plotted as a function of time under the condition of $(A)$ and (B), respectively. ( $E$ and F) ICP-MS results of Cu concentration per HeLa cell pretreated with dynasore, $C P Z$, filipin, and Cyt $D$ at $4{ }^{\circ} \mathrm{C}$ and then treated with the CuS-new NP (E) and CuS-old NP (F) conditions, respectively, with untreated cells as the control.

intensities showed a linear increase (Fig. 4C); however, for addition of CuS-old NPs, the linear increase was only observed within the first $30 \mathrm{~min}$, after which, the peak intensity at 3255 $\mathrm{cm}^{-1}$ remained nearly unchanged while the peak intensity at $3683 \mathrm{~cm}^{-1}$ showed a dramatic growth (Fig. 4D). For CuS-old NPs, the coordination of $\mathrm{Cu}^{2+}$ with PEG relative to that of CuSnew NPs will decrease the electronegativity of the NPs (Fig. 3B) and greatly weaken the electrostatic repulsion forces between NPs and the negatively charged cell plasma membrane, thus accelerating and increasing the adsorption of NPs on the cell membrane in the same period of time, ${ }^{4}$ which may result in the saturated adsorption within $30 \mathrm{~min}$. The progressive adsorption of NPs could continually interrupt the conformation of the lipid and reorient the interfacial water molecules, resulting in a continuous change of the absorption of the interfacial water. After saturated adsorption, the strong hydrogen bond network among the water molecules near the cell membrane could remain relatively stable, resulting in unchanged intensity for the peak at $3255 \mathrm{~cm}^{-1}$. More interestingly, due to this phenomenon, the peak at $1577 \mathrm{~cm}^{-1}$ was gradually shifted to $1601 \mathrm{~cm}^{-1}$ with a similar tendency for the change of the peak intensity at $3683 \mathrm{~cm}^{-1}$ (Fig. 4C, blue line). Accompanied by the adsorption of CuS-old NPs on the surface of the cell membrane, the copper ions coordinated on the surface of the NPs also gradually approach the surface of the cell membrane and interact with the cell membrane, thus leading to the shift of the

maximum absorption peak from $\sim 1577 \mathrm{~cm}^{-1}$ to $1601 \mathrm{~cm}^{-1}$ due to the coordination of $\mathrm{Cu}^{2+}$, which shows a similar tendency to that of the fast increase of the intensity for the peak at 3683 $\mathrm{cm}^{-1}$, suggesting that the interaction of surface $\mathrm{Cu}^{2+}$ caused a strong disturbance to the hydrogen-bond network of interfacial water. However, this phenomenon is dramatically different from that induced by pure $\mathrm{Cu}^{2+}$ interaction (Fig. $3 \mathrm{~A}(\mathrm{~d})$ ). Considering the interaction between copper ions that coordinate on the surface of nanomaterials and cell membranes, it is possible that the significant enhancement of the absorption at $3683 \mathrm{~cm}^{-1}$ may be related to the endocytosis of nanomaterials. Therefore, the different spectral changes caused by the interaction of CuS-new NPs and CuS-old NPs with cells may reflect different uptakes.

To prove this hypothesis, inductively coupled plasma mass spectroscopy (ICP-MS) was used to quantify the uptake of the two kinds of nanoparticles by HeLa cells (Fig. 4E and F), which shows an elevated content of $\mathrm{Cu}$ for CuS-old-treated cells compared with that of CuS-new-treated cells, suggesting an enhanced uptake of CuS NPs via internalization and membrane-bound possibly due to the strengthened association and binding avidity of NPs by exposed $\mathrm{Cu}$ ions on the surface of CuS NPs. Treatment of cells at $4{ }^{\circ} \mathrm{C}$ resulted in a dramatic decrease of the uptake of both NPs, suggesting energy-dependent endocytosis. If the cells were treated with chlorpromazine (CPZ, clathrin inhibitor) and dynasore (dynamin inhibitor), respectively, the cellular uptake of CuS-old NPs could be significantly inhibited, while having less effect on the uptake of CuS-new NPs. After treatment of cells with filipin (caveolae inhibitor) or Cyt D (inhibitor of actin polymerization related phagocytosis and clathrin/caveolin independent endocytosis), only the uptake of CuS-new NPs was affected by the treatment of Cyt D. These results demonstrate that the endocytosis of CuSold NPs is mainly clathirin-mediated, while that of CuS-new NPs is through clathirin-mediated and clathrin- and caveolae-independent pathways. Interestingly, we found that dynasore and $\mathrm{CPZ}$ also affected the relative strength of water peaks induced by the interaction of CuS-old NPs with cells (Fig. S4†). The comparison of the ratio of peak intensity $I_{3683 / 3255}$ in the presence and absence of inhibitors also indicates the clathirinmediated endocytosis of CuS-old NPs (Fig. S4F $\dagger$ ), which further suggests that the significant enhancement in the intensity of the peak at $3683 \mathrm{~cm}^{-1}$ could be induced by endocytosis of NPs. The intracellular membrane mass redistribution with NP internalization ${ }^{41}$ could facilitate the entry of hydrated PEG-CuS NPs into the hydrophobic backbone of the plasma membrane and then greatly enhance the amount of water molecules with disturbed hydrogen bonding.

\section{SEIRAS study of photothermal-induced cell death}

Compared with CuS-new NPs, the enhanced cell uptake of CuSold NPs due to the weak electrostatic repulsion forces (Fig. 3B) as evaluated from the $\mathrm{Cu}$ content measured by ICP-MS (Fig. $4 \mathrm{E}$ and F) will inevitably enhance the photothermal effect, resulting in more cell death under the same power irradiation (Fig. 5A). To further reveal the molecular mechanism of such 

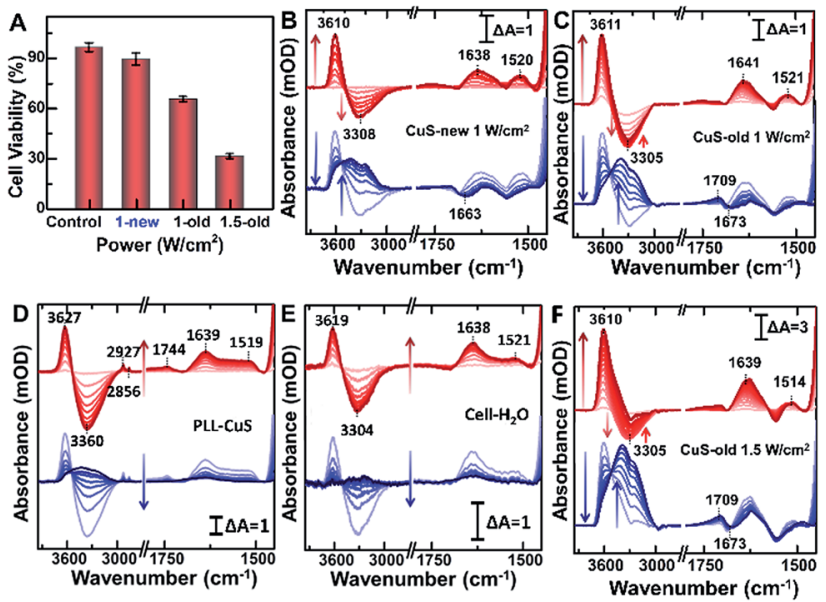

Fig. 5 (A) Trypan blue exclusion test of cell viability without and with $980 \mathrm{~nm}$ irradiation ( 1 and $1.5 \mathrm{~W} \mathrm{~cm}^{-2}$ ). Time-dependent SEIRA spectra collected from CuS-new (B) and CuS-old (C) NP treated HeLa cells, the NP-treated PLL surface (D), the NP-untreated cell-coated surface (E) illuminated at $1 \mathrm{~W} \mathrm{~cm}^{-2}$ and CuS-old NP treated cells at $1.5 \mathrm{~W} \mathrm{~cm}^{-2}$ (F) on the $\mathrm{rGO}-\mathrm{Au} / \mathrm{Au}$ substrate by taking CuS incubated cells on the $\mathrm{rGO}-\mathrm{Au} / \mathrm{Au}$ substrate immersed in PBS as a reference. Red lines (upper panel, 0-20 min): at the start of the illumination; blue lines (lower panel, 0-20 $\mathrm{min}$ ): at the end of the illumination.

a difference, the hyperthermia-induced cellular spectra were monitored under $980 \mathrm{~nm}$ laser irradiation at $1 \mathrm{~W} \mathrm{~cm}^{-2}$ for 20 min by taking HeLa cells incubated with two kinds of PEG-CuS NPs at room temperature as reference spectra, respectively (Fig. 5B and C). For CuS-new NP treated cells, it is interesting to observe the opposite intensity changes of the $\nu(\mathrm{OH})$ stretching band of water molecules with an increase at $\sim 3610 \mathrm{~cm}^{-1}$ and a decrease at $\sim 3300 \mathrm{~cm}^{-1}$ as a function of illumination time (Fig. 5B, upper panel, red lines) possibly due to a lateral disordered orientation for the coupled multimer water to the lipid and the decrease of near-bulk water upon heating, ${ }^{51}$ just as the phenomena observed in the control groups PLL-coated (Fig. 5D) and NP-untreated cell-coated surface (Fig. 5E) under identical conditions. However, for CuS-old NP treated cells, the negative water band at $\sim 3300 \mathrm{~cm}^{-1}$ was partly recovered at the end (Fig. 5C). More significant is that the SEIRA spectra in the control groups were nearly recovered to the initial state after stopping the illumination (Fig. 5D and E, lower panel, blue lines); however, significant spectral changes can be observed in the fingerprint region for CuS-NP treated cells, suggesting that the disturbance to the interfacial water and the configuration of the cellular membrane could be recovered after the surface was gradually cooled without the effect of NPs. It is worthy to note that a more obvious peak appeared at $1709 \mathrm{~cm}^{-1}$ for the cells treated with CuS-old NPs (Fig. 5C, lower panel) than those treated with CuS-new NPs (Fig. 4B, lower panel), which could be the reason for the recovery of the negative peak at $\sim 3300 \mathrm{~cm}^{-1}$ as shown in Fig. 5C (upper panel).

To further verify the hypothesis, we recorded the hyperthermia-induced cellular spectra under irradiation at $1.5 \mathrm{~W}$ $\mathrm{cm}^{-2}$ since such a condition could induce more cell death (Fig. 5A). Indeed, we observed that the peak at $1709 \mathrm{~cm}^{-1}$ appeared even under illumination, and the recovery of the negative peak was more obvious at $\sim 3300 \mathrm{~cm}^{-1}$, almost restored to the baseline level (Fig. 5F, upper panel). A positive-going band at $1709 \mathrm{~cm}^{-1}$ may be assigned to $\nu(\mathrm{C}=\mathrm{O})$ stretching vibration of phosphatidylserine (PS), ${ }^{57}$ a spectral marker of apoptosis associated with membrane changes such as the loss of membrane phospholipid asymmetry, cell shrinkage and cell membrane blubbing (Fig. S5D $\dagger$ ). These cell membranes flip from the inner to the outer surface of the plasma membrane (vide infra) and could further bind water molecules to rearrange the H-bonding network near the cellular membrane along with the newly entered water molecules after cell contraction.

To further reveal the mechanism of apoptosis, we carefully compared the steady-state SEIRA spectra of cells treated with different nanoparticles and after stopping irradiation and cooling to room temperature (Fig. 6). In addition to the positive peak at $1709 \mathrm{~cm}^{-1}$, the obviously negative peaks in amide I and amide II and $\nu\left(\mathrm{CH}_{3}\right)$ regions further indicate that the cell adhered to the extracellular matrix was partially desorbed from the surface as water molecules moved into the interface accompanied by an increase in the intensity of the interfacial water at $3000-3800 \mathrm{~cm}^{-1}, 56$ and at this time, cells lost their bioactivities and underwent apoptosis. ${ }^{40}$ The inconsistent maximally negative peak of amide I at $1673 \mathrm{~cm}^{-1}$ and 1663 $\mathrm{cm}^{-1}$ produced by the cells treated with CuS-old and CuS-new NPs might suggest the different membrane protein receptors for CuS-old and CuS-new NP binding. Based on the above analysis of the ICP results, CuS NPs will adopt different endocytosis pathways at different stages. The clathirin-mediated endocytosis of CuS-old NPs is mainly through the membrane protein receptor $\mathrm{Yxx} \Phi$ (tyrosine-amino acid-hydrophobic residue) mediated by the AP2 $\mu 2$ fragment with an elongated banana-shaped seven-bladed $\beta$ propeller, leading to the maximum peak position of amide I closer to $1673 \mathrm{~cm}^{-1}$ (Table $\mathrm{S} 1 \dagger) .{ }^{58,59}$ Because of the coordination of $\mathrm{Cu}$ ions with CuS-old

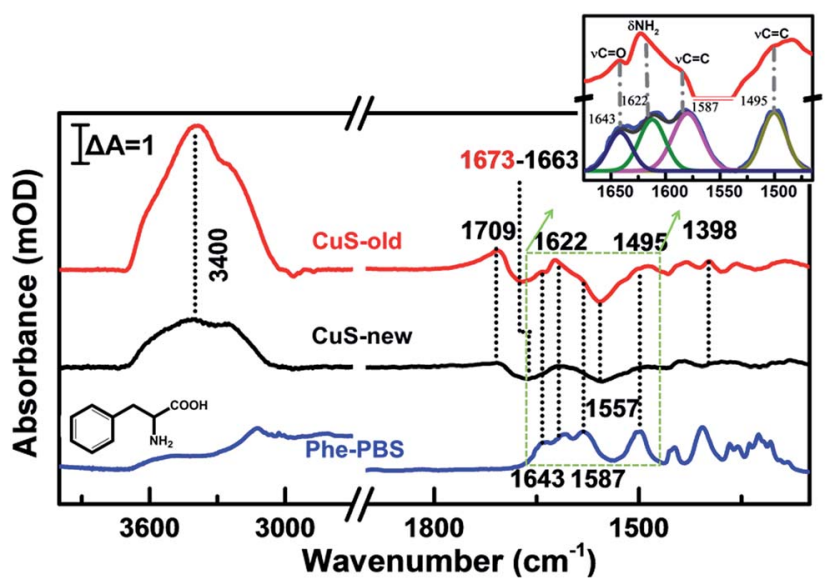

Fig. 6 Comparison of the steady-state SEIRA spectra of cells treated with CuS-new (black) and CuS-old (red) after stopping irradiation by taking CuS incubated cells on the rGO-Au/Au substrate immersed in PBS as a reference, and the spectrum of Phe dissolved in PBS and then dried on the Si wafer (blue). Inset: magnified spectra ranging from 1675 $\mathrm{cm}^{-1}$ to $1465 \mathrm{~cm}^{-1}$ with peak fitting. 
NPs, the surface $\mathrm{Cu}$ ions could also bind to certain membrane proteins. ${ }^{43}$ In comparison, the clathrin- and caveolae-independent pathways have a significant influence on endocytosis of CuS-new NPs, but the mechanisms remain poorly understood. ${ }^{60,61}$ However, compared with different peak positions, we believe that the protein receptors they act on are different.

According to the reported results, the inhibition of the phenylalanine (Phe) metabolism pathway could elevate the levels of Phe, its derivatives or contained peptides, thus inducing cell apoptosis during PTT therapy. ${ }^{62,63}$ Interestingly, several positive peaks did appear between negative peaks of amide I and amide II (Fig. 6, red line), proving that some molecules approach the surface of the substrate while membrane protein receptors move from the surface of the substrate. Thus, we have carefully analyzed the spectra between $1675 \mathrm{~cm}^{-1}$ and $1465 \mathrm{~cm}^{-1}$ with peak fitting processing in the Fig. 6 inset. Compared to the characteristic spectral pattern of chemical fingerprint absorption peaks of hydrophobic aromatic amino acids - Phe at $\sim 1643,1622,1587$ and $1495 \mathrm{~cm}^{-1}$, which are attributed to the ring substituent $\nu(\mathrm{C}=\mathrm{O}), \delta\left(\mathrm{NH}_{2}\right), \nu(\mathrm{C}=\mathrm{C})$ ring vibration (Table $\mathrm{S} 2 \dagger$ ), we found that these characteristic absorption peaks are basically consistent with steady-state SEIRA spectra of cells after PTT. ${ }^{64,65}$ The results demonstrate that Phe metabolism should be disturbed in cell apoptosis. Additionally, according to the cell phenotype, apoptosis was induced by the mitochondrial mediated Rho/ROCK pathway, in which myosin phosphatase target subunit 1 was cleaved by caspase-3 at Asp-884 to inhibit myosin II binding, and this will lead to an increasing phenylalanine levels in cells. ${ }^{62}$ The loss of selective permeability and the cellular membrane becoming more permeable upon apoptosis may result in the leakage of intracellular Phe ${ }^{66}$ and is thus detectable by SEIRAS together with the signal of some buried hydrophobic amino acids exposed during protein inactivation. ${ }^{63}$

\section{Conclusions}

Here, we construct a hybrid plasma film of Au decorated with a rGO-Au nanostructure via simultaneous reduction of $\mathrm{NaAuClO}_{4}$ and GO solution on the Si substrate, which displays an enhanced local electromagnetic field and good biocompatibility to the attached living cells, thus allowing monitoring in situ and in real time the interaction between $\mathrm{NP}_{\mathrm{S}}$ and living cells by SEIRAS. According to the fingerprint characteristics of SEIRAS, we could reveal that copper ions produced during the degradation of CuS NPs can cooperate with PEG modified on the surface of nanoparticles, which can significantly change the surface properties of nanomaterials and thus change the interaction with cells. The coordinated copper ions significantly reduce the electronegativity of nanomaterials, thus reducing the repulsion between materials and cell membranes and accelerating their interaction. The interaction between copper ions on the surface of materials and cell membranes changes the pathway of materials entering cells, increases the uptake of materials by cells, and enhances the water content of weak hydrogen bonding at the interface of cell membranes during endocytosis. Photothermal effect can transfer intracellular phospholipids to extracellular space, further changing the arrangement of interface water, meanwhile increasing the content of hydrophobic phenylalanine, which can induce apoptosis. The high sensitivity and fingerprint characteristics enable SEIRAS to reveal dynamic changes of the surface properties of PEG-coated CuS NPs and how they alter the interaction of nanomaterials with living cells for the first time.

\section{Experimental section}

\section{Preparation of the rGO-Au-decorated Au plasmonic substrate}

The Au film decorated with $\mathrm{rGO}-\mathrm{Au}(\mathrm{rGO}-\mathrm{Au} / \mathrm{Au})$ was electroless deposited onto the Si prism or wafer, which was polished with an $\mathrm{Al}_{2} \mathrm{O}_{3}$ slurry $(1.0 \mu \mathrm{m})$, followed by washing thoroughly with deionized water. After immersion in a $40 \mathrm{wt} \% \mathrm{NH}_{4} \mathrm{~F}$ aqueous solution for $3 \mathrm{~min}$, the $\mathrm{rGO}-\mathrm{Au} / \mathrm{Au}$ film was prepared by exposing the treated surface to a $1: 1: 1(\mathrm{v} / \mathrm{v} / \mathrm{v})$ mixture of $0.3 \mathrm{M} \mathrm{Na}_{2} \mathrm{SO}_{3}+0.1 \mathrm{M} \mathrm{Na}_{2} \mathrm{~S}_{2} \mathrm{O}_{3}+0.1 \mathrm{M} \mathrm{NH}_{4} \mathrm{Cl}, 3 \% \mathrm{HF}$, and 1.2 $\mathrm{mg} \mathrm{mL}^{-1} \mathrm{NaAuCl}_{4}$ aqueous solution mixed with $2.5 \mathrm{mg} \mathrm{mL}^{-1}$ GO for $4 \mathrm{~min}$ at $55^{\circ} \mathrm{C}$. The obtained substrate was cleaned by electrochemical oxidation-reduction scanning in $0.1 \mathrm{M} \mathrm{H}_{2} \mathrm{SO}_{4}$ solution over the potential range of $0.1-1.4 \mathrm{~V}$ versus $\mathrm{Ag} / \mathrm{AgCl}$. At last, the $\mathrm{rGO}-\mathrm{Au} / \mathrm{Au}$ film coated $\mathrm{Si}$ prism was mounted on a home-built poly(trifluorochloroethylene) cell with a Viton Oring. In order to obtain the desired enhancement effect for sulfhydryl and aromatic molecules, the $\mathrm{NaAuCl}_{4}$ aqueous solution mixed with different masses of GO dispersion $\left(m_{\mathrm{Au}} / m_{\mathrm{GO}}=4.8-66\right)$ was used to detect $p$-aminothiophenol ( $p$-ATP) and methylene blue (MB) molecules.

To evaluate the enhancement factor (EF) of the rGO-Au/Au plasmonic substrate, a reference spectrum of the bare $\mathrm{Si}$ or rGO$\mathrm{Au} / \mathrm{Au}$-coated Si prism was first recorded and then $\sim 0.32 \mu \mathrm{g}$ $(\sim \text { monolayer thickness })^{25}$ of $p$-ATP ethanol solution was dropped on the surface of the bare $\mathrm{Si}$ and rGO-Au/Au-coated $\mathrm{Si}$ prism, respectively. The sample spectra were recorded until total evaporation of ethanol by averaging 521 scans at a spectral resolution of $4 \mathrm{~cm}^{-1}$.

\section{Immobilization of cells on the rGO-Au/Au film}

Before culturing HeLa cells, the home-made poly(trifluorochloroethylene) cell and necessary experimental tools were sterilized with $70 \%$ ethanol under UV irradiation. $2 \mathrm{~mL}$ of cell suspension $\left(5 \times 10^{5}\right.$ cell per $\left.\mathrm{mL}\right)$ was seeded on the poly-L-lysine layer $\left(0.1 \mathrm{mg} \mathrm{mL}^{-1} \mathrm{PLL}\right)$ modified $\mathrm{rGO}-\mathrm{Au} / \mathrm{Au}$ film. After incubation for $24 \mathrm{~h}$, the IR cell was mounted on a SEIR spectrometer. After washing three times with PBS, cells were exposed to $100 \mu \mathrm{g}$ $\mathrm{mL}^{-1}$ of PEG-CuS NPs by adding $25 \mu \mathrm{L}$ PEG-CuS NP aqueous solution $\left(4 \mathrm{mg} \mathrm{mL}^{-1}\right)$ into a volume of $1 \mathrm{~mL}$ of PBS. ${ }^{40} \mathrm{CuS} \mathrm{NP}$ induced SEIRA spectra were obtained by taking cells in PBS as a reference spectrum. After incubation with $100 \mu \mathrm{g} \mathrm{mL} \mathrm{mL}^{-1}$ PEGCuS NPs for $2 \mathrm{~h}$, the cells were washed three times with PBS, followed by irradiation for $20 \mathrm{~min}$ using a $980 \mathrm{~nm}$ diode laser with a power of 1 and $1.5 \mathrm{~W} \mathrm{~cm}^{-2}$. As the control experiments, $25 \mu \mathrm{L} \mathrm{H}_{2} \mathrm{O}$, the supernatant of CuS NPs (20 day) and $5 \mathrm{mM} \mathrm{CuCl}_{2}$ were used to replace CuS NPs and added into the ATR chambers. Unless noted specifically, the control experiments were 
performed following the same protocol and each measurement was repeated in triplicate.

Cell viability on the $\mathrm{rGO}-\mathrm{Au} / \mathrm{Au}$ substrate was roughly assessed using a top-view optical microscope for cell monolayer integrity and morphology, and the trypan blue exclusion test to stain dead cells. Cells were trypsinized and resuspended in trypan blue $\left(0.4 \%, \mathrm{~g} \mathrm{ml}^{-1}\right)$ for $3 \mathrm{~min}$. Cell viability was calculated under $10 \times$ magnification using a hematocytometer. The percentage of cell viability was calculated as follows: $N_{\text {viable cells }} /$ $N_{\text {total cells }} \times 100 \%$.

To more directly explore the endocytic mechanism of CuSPEG NPs internalized into HeLa cells, cells were pretreated with various inhibitors including dynasore $\left(30 \mu \mathrm{g} \mathrm{mL} \mathrm{m}^{-1}\right.$, dynamin inhibitor), chlorpromazine (CPZ, $10 \mu \mathrm{g} \mathrm{mL}{ }^{-1}$, clathrin inhibitor), filipin (10 $\mathrm{g} \mathrm{mL}^{-1}$, caveolae inhibitor $)$, and Cyt D $(1 \mu \mathrm{mol}$ $\mathrm{L}^{-1}$, an inhibitor of actin polymerization related phagocytosis and clathrin/caveolin independent endocytosis) for $1 \mathrm{~h}$ at $25{ }^{\circ} \mathrm{C}$ or $4{ }^{\circ} \mathrm{C}$ (energy independent pathway). After culturing with CuSPEG NPs, cells were washed with PBS three times, trypsinized, resuspended, counted, and centrifuged, and the cell pellet was digested in $1 \mathrm{~mL}$ of aqua regia $\left(V_{\mathrm{HCl}}: V_{\mathrm{HNO}_{3}}=3: 1\right)$. Cell concentrations were determined by hemacytometry and the intracellular copper content was quantified using ICP-MS with parts per billion sensitivity. In control, cells were placed in $1 \mathrm{~mL}$ PBS without nanoparticles.

\section{Simulation}

To simplify, the ellipsoid gold nanoparticle $\left(R_{1}=30 \mathrm{~nm} ; R_{2}=10\right.$ $\mathrm{nm}$ ) obtained from the AFM image and a rGO layer of $4 \mathrm{~nm}$ thickness inferred from Raman data were considered, and simulation was performed by using the 3D finite-difference time-domain (FDTD) method on the basis of time varying electromagnetic Maxwell's equations. ${ }^{33,34}$ The incident light with a wavelength range from 2.5 to $10 \mu \mathrm{m}$ propagating along the $z$ direction was normally illuminated on the surface. Periodic boundary conditions and perfectly matched layer conditions were used to evaluate near-field enhancement data $\left|E / E_{0}\right|$ of the rGO-Au/Au film. The optical permittivity parameters of $\mathrm{Au}$ and rGO used in simulation were extracted from the data of Palik and Hwang. ${ }^{67,68}$

\section{Plasmon nano-imaging}

Scattering-type scanning near-field optical microscopy (sSNOM, Molecular Vista) used for this work was based on an AFM probe (a gold coated Si cantilever, $70 \mathrm{~nm}$ tapping amplitude and $270 \mathrm{kHz}$ resonance frequency), which was illuminated by focused infrared light from a pulsed quantum cascade laser (QCL, Block Engineering). The plasmon nano-imaging of the sample could be obtained simultaneously via mapping the topography and the near-field scattered intensity detected using a liquid-nitrogen-cooled MCT detector. In order to suppress near field contribution from the tip-sample region, a versatile "Generalized Lock-In Amplifier" (GLIA) approach, which calculates the amplitude and phase of the scattered field, was used in the first harmonic modulation..$^{25,69}$

\section{Conflicts of interest}

There are no conflicts to declare.

\section{Acknowledgements}

This work was financially supported by the Joint Sino-German Research Projects (21761132028), the National Natural Science Foundation of China (21675149, 21705146, 21874125, and 21877107), the Key Research Program of Frontier Sciences, CAS (QYZDY-SSW-SLH019), and the Science and Technology Development Program of Jilin Province (20170414037GH and 20190201074JC), and K. C. Wong Education Foundation.

\section{Notes and references}

1 G. Brumfiel, Nature, 2003, 424, 246.

2 M. Ferrari, Nat. Rev. Cancer, 2005, 5, 161.

3 L. A. Dykman and N. G. Khlebtsov, Chem. Rev., 2013, 114, 1258-1288.

4 A. Albanese, P. S. Tang and W. C. W. Chan, Annu. Rev. Biomed. Eng., 2012, 14, 1-16.

5 H. K. Baca, C. Ashley, E. Carnes, D. Lopez, J. Flemming, D. Dunphy, S. Singh, Z. Chen, N. G. Liu, H. Y. Fan, G. P. Lopez, S. M. Brozik, M. Werner-Washburne and C. J. Brinker, Science, 2006, 313, 337-341.

6 A. Albanese, C. D. Walkey, J. B. Olsen, H. Guo, A. Emili and W. C. Chan, ACS Nano, 2014, 8, 5515-5526.

7 P. Dogra, N. L. Adolphi, Z. Wang, Y.-S. Lin, K. S. Butler, P. N. Durfee, J. G. Croissant, A. Noureddine, E. N. Coker, E. L. Bearer, V. Cristini and C. J. Brinker, Nat. Commun., 2018, 9, 1-14.

8 L. Guo, I. Panderi, D. D. Yan, K. Szulak, Y. Li, Y. T. Chen, H. Ma, D. B. Niesen, N. Seeram, A. Ahmed, B. Yan, D. Pantazatos and W. Lu, ACS Nano, 2013, 7, 8780-8793.

9 Y. Yong, X. J. Cheng, T. Bao, M. Zu, L. Yan, W. Y. Yin, C. C. Ge, D. L. Wang, Z. J. Gu and Y. L. Zhao, ACS Nano, 2015, 9, 12451-12463.

10 B. Ding, Y. Tian, Y. Pan, Y. Shan, M. Cai, H. Xu, Y. Sun and H. Wang, Nanoscale, 2015, 7, 7545-7549.

11 P. R. Griffiths and J. A. De Haseth, in Fourier transform infrared spectrometry, ed. J. D. Winefordner, Springer International Publishing, 2007, pp. 2379-2380.

12 H. Muhamadali, M. Chisanga, A. Subaihi and R. Goodacre, Anal. Chem., 2015, 87, 4578-4586.

13 M. J. Baker, J. Trevisan, P. Bassan, R. Bhargava, H. J. Butler, K. M. Dorling, P. R. Fielden, S. W. Fogarty, N. J. Fullwood, K. A. Heys, C. Hughes, P. Lasch, P. L. Martin-Hirsch, B. Obinaju, G. D. Sockalingum, J. Sulé-Suso, R. J. Strong, M. J. Walsh, B. R. Wood, P. Gardner and F. L. Martin, Nat. Protoc., 2014, 9, 1771-1791.

14 D. R. Whelan, K. R. Bambery, L. Puskar, D. McNaughton and B. R. Wood, Analyst, 2013, 138, 3891-3899.

15 X. Jiang, E. Zaitseva, M. Schmidt, F. Siebert, M. Engelhard, R. Schlesinger, K. Ataka, R. Vogel and J. Heberle, Proc. Natl. Acad. Sci. U. S. A., 2008, 105, 12113-12117. 
16 A. Barth, Biochim. Biophys. Acta, Bioenerg., 2007, 1767, 10731101.

17 D. C. Fernandez, R. Bhargava, S. M. Hewitt and I. W. Levin, Nat. Biotechnol., 2005, 23, 469-474.

18 K. L. A. Chan and S. G. Kazarian, Chem. Soc. Rev., 2016, 45, 1850-1864.

19 B. R. Wood, L. Chiriboga, H. Yee, M. A. Quinn, D. McNaughton and M. Diem, Gynecol. Oncol., 2004, 93, 59-68.

20 C. Lima, V. Goulart, L. Côrrea, T. Pereira and D. Zezell, Int. J. Mol. Sci., 2015, 16, 6621-6630.

21 M. Osawa, in Surface-enhanced infrared absorption, ed. S. Kawata, Springer International Publishing, 2001, pp. 163-187.

22 L. Wu, L. Zeng and X. Jiang, J. Am. Chem. Soc., 2015, 137, 10052-10055.

23 Y. Liu, W. J. Bao, Q. W. Zhang, J. Li, J. Li, J. J. Xu, X. H. Xia and H. Y. Chen, Anal. Chem., 2018, 90, 12979-12985.

24 S. Lal, N. K. Grady, J. Kundu, C. S. Levin, J. B. Lassiter and N. J. Halas, Chem. Soc. Rev., 2008, 37, 898-911.

25 F. J. Cao, L. Wu, Y. D. Ruan, J. Bai and X. E. Jiang, Anal. Chem., 2018, 90, 6526-6531.

26 Y. Li, Q. Lu, H. Liu, J. Wang, P. Zhang, H. Liang, L. Jiang and S. Wang, Adv. Mater., 2015, 27, 6848-6854.

27 J. Chen, B. Yao, C. Li and G. Shi, Carbon, 2013, 64, 225-229. 28 D. R. Dreyer, S. Park, C. W. Bielawski and R. S. Ruoff, Chem. Soc. Rev., 2010, 39, 228-240.

29 M. Iliut, C. Leordean, V. Canpean, C.-M. Teodorescu and S. Astilean, J. Mater. Chem. C, 2013, 1, 4094.

30 K. N. Kudin, B. Ozbas, H. C. Schniepp, R. K. Prud'homme, I. A. Aksay and R. Car, Nano Lett., 2008, 8, 36-41.

31 S. Stankovich, D. A. Dikin, R. D. Piner, K. A. Kohlhaas, A. Kleinhammes, Y. Jia, Y. Wu, S. T. Nguyen and R. S. Ruoff, Carbon, 2007, 45, 1558-1565.

32 G. Eda, G. Fanchini and M. Chhowalla, Nat. Nanotechnol., 2008, 3, 270-274.

33 Y. Wang, H. Chen, M. Sun, Z. Yao, B. Quan, Z. Liu, Y. Weng, J. Zhao, C. Gu and J. Li, Carbon, 2017, 122, 98-105.

34 W. J. Bao, Z. D. Yan, M. Wang, Y. Zhao, J. Li, K. Wang, X. H. Xia and Z. L. Wang, Chem. Commun., 2014, 50, 7787-7789.

35 M. Osawa, N. Matsuda, K. Yoshii and I. Uchida, J. Phys. Chem., 1994, 98, 12702-12707.

36 Z. Q. Yu and S. S. C. Chuang, J. Phys. Chem. C, 2007, 111, 13813-13820.

37 J. Varani, D. R. Inman, S. E. G. Fligiel and W. J. Hillegas, Cytotechnology, 1993, 13, 89-98.

38 G. Ramer, A. Balbekova, A. Schwaighofer and B. Lendl, Anal. Chem., 2015, 87, 4415-4420.

39 C. S. Shan, H. F. Yang, D. X. Han, Q. X. Zhang, A. Ivaska and L. Niu, Langmuir, 2009, 25, 12030-12033.

40 P. L. Fale, A. Altharawi and K. L. A. Chan, Biochim. Biophys. Acta, Mol. Cell Res., 2015, 1853, 2640-2648.

41 T. Suutari, T. Silen, D. Şen Karaman, H. Saari, D. Desai, E. Kerkelä, S. Laitinen, M. Hanzlikova, J. M. Rosenholm, M. Yliperttula and T. Viitala, Small, 2016, 12, 6289-6300.

42 J. Li, B. Zheng, Q.-W. Zhang, Y. Liu, C.-F. Shi, F.-B. Wang, K. Wang and X.-H. Xia, Journal of Analysis and Testing, 2017, 1, 1-8.
43 B.-E. Kim, T. Nevitt and D. J. Thiele, Nat. Chem. Biol., 2008, 4, 176-185.

44 E. Georgatsou and D. Alexandraki, Yeast, 1999, 15, 573-584. 45 A. A. Finegold, K. P. Shatwell, A. W. Segal, R. D. Klausner and

A. Dancis, J. Biol. Chem., 1996, 271, 31021-31024.

46 T. Furukawa, M. Komatsu, R. Ikeda, K. Tsujikawa and S. Akiyama, Curr. Med. Chem., 2008, 15, 3268-3278.

47 J. Gerbrand Mesu, T. Visser, F. Soulimani, E. E. van Faassen, P. de Peinder, A. M. Beale and B. M. Weckhuysen, Inorg. Chem., 2006, 45, 1960-1971.

48 J. G. Mesu, T. Visser, F. Soulimani, E. E. van Faassen, P. de Peinder, A. M. Beale and B. M. Weckhuysen, Inorg. Chem., 2006, 45, 1960-1971.

49 R. Falahat, M. Wiranowska, R. Toomey and N. Alcantar, Vib. Spectrosc., 2016, 87, 164-172.

50 B. Ma, S. Wang, F. Liu, S. Zhang, J. Duan, Z. Li, Y. Kong, Y. Sang, H. Liu, W. Bu and L. Li, J. Am. Chem. Soc., 2018, 141, 849-857.

51 H. Binder, Eur. Biophys. J., 2006, 36, 265-279.

52 M. J. Stein, T. Weidner, K. McCrea, D. G. Castner and B. D. Ratner, J. Phys. Chem. B, 2009, 113, 11550-11556.

53 D. Naumann, Infrared Spectroscopy of Cells, Tissues, and Biofluids, Springer, 2013.

54 X. Cong, M. F. Poyton, A. J. Baxter, S. Pullanchery and P. S. Cremer, J. Am. Chem. Soc., 2015, 137, 7785-7792.

55 L. Zeng, Chem.-Eur. J., 2017, 23, 15491-15497.

56 Y. Nagata and S. Mukamel, J. Am. Chem. Soc., 2010, 132, 6434-6442.

57 B. B. Wu, Y. P. Gong, X. H. Wu, Y. Y. Chen, F. F. Chen, L. T. Jin, B. R. Cheng, F. Hu and B. Xiong, J. Transl. Med., 2015, 13, 108. 58 M. Marsh and H. T. McMahon, Science, 1999, 285, 215-220. 59 L. M. Traub, M. A. Downs, J. L. Westrich and D. H. Fremont, Proc. Natl. Acad. Sci. U. S. A., 1999, 96, 8907-8912.

60 S. D. Conner and S. L. Schmid, Nature, 2003, 422, 37-44.

61 R. G. Anderson and K. Jacobson, Science, 2002, 296, 1821-1825.

62 M. R. K. Ali, Y. Wu, T. Han, X. Zang, H. Xiao, Y. Tang, R. Wu, F. M. Fernández and M. A. El-Sayed, J. Am. Chem. Soc., 2016, 138, 15434-15442.

63 M. Aioub and M. A. El-Sayed, J. Am. Chem. Soc., 2016, 138, 1258-1264.

64 L. K. Tamm and S. A. Tatulian, Q. Rev. Biophys., 1997, 30, 365-429.

65 S. Y. Venyaminov and N. N. Kalnin, Biopolymers, 1990, 30, 1243-1257.

66 H. Hagberg, A. Lehmann, M. Sandberg, B. Nyström, I. Jacobson and A. Hamberger, J. Cereb. Blood Flow Metab., 1985, 5, 413-419.

67 E. Jung, S. Lee, S. Roh, E. Hwang, J. Lee, H. Lee and J. Hwang, J. Phys. D: Appl. Phys., 2014, 47, 265306.

68 E. D. Palik, Handbook of optical constants of solids, Academic press, New York, 1998.

69 A. Bruyant, J. Vaillant, T.-H. Wu, Y. Zhu, Y. Huang and A. Al Mohtar, Interferometry Using Generalized Lock-in Amplifier ( $G$ LIA): A Versatile Approach for Phase-Sensitive Sensing and Imaging, inTech, Croatia, 2017. 